\title{
Article
}

\section{Blogging It: Encouraging Reflective Thinking for Architectural Practice.}

Barrett, Jennifer

Available at https://clok.uclan.ac.uk/1548/

Barrett, Jennifer orcid iconORCID: 0000-0002-6795-1615 (2010) Blogging It: Encouraging Reflective Thinking for Architectural Practice. CEBE Transactions, 7 (1). pp. 38-50. ISSN 1745-0322

It is advisable to refer to the publisher's version if you intend to cite from the work.

For more information about UCLan's research in this area go to

http://www.uclan.ac.uk/researchgroups/ and search for < name of research Group>.

For information about Research generally at UCLan please go to http://www.uclan.ac.uk/research/

All outputs in CLoK are protected by Intellectual Property Rights law, including Copyright law. Copyright, IPR and Moral Rights for the works on this site are retained by the individual authors and/or other copyright owners. Terms and conditions for use of this material are defined in the policies page.

\section{CLoK}

Central Lancashire online Knowledge www.clok.uclan.ac.uk 


\title{
Blogging It: Encouraging Reflective Thinking for Architectural Practice
}

\author{
Jennifer Barrett, Lecturer in Architecture
}

School of Built and Natural Environment, University of Central Lancashire, UK

Email: jebarrett@uclan.ac.uk

\begin{abstract}
In a period of dynamic change for architectural professionalism and practice, it is becoming increasingly relevant to identify effective ways for students to develop reflective thinking which they will need to manage their transition from student to practitioner and be able to respond to industry change throughout their careers. This paper reports upon an assessment technique using an online blog which was used to capture students' real-time and reflective thoughts. The key elements of the brief are discussed and the outcomes of the assessment, which included learning experiences which were planned for as well as some which were not predicted.
\end{abstract}

Keywords: Reflective Learning, Architectural Practice Management, E-learning, Experiential Learning, Blog 


\section{Introduction}

Since Sir John Egan communicated the changes necessary to achieve project success in Rethinking Construction in 1998, the construction industry has changed. The role of the architectural practitioner has evolved in response to these significant changes to the professional environment. The foundations of the profession have been shaken and traditional project team hierarchies inverted. This dynamic change in the professional role of architects is given impetus by the development of the 'integrated team' (Egan, 1998) in which its members now operate as peers, rather than subordinate to the architect, as tradition has previously dictated. This apparent diminishing of the architect's role in the multidisciplinary team urgently requires practitioners to develop their generic skills in teamworking and decision-making alongside their more established skills in design and building.

When architects find themselves part of this team, they will need to make sure that they can operate effectively within it, playing their part to enhance collective performance towards a functionally, structurally, aesthetically and of course, commercially successful outcome. Effective teamworking, paradoxically, requires self awareness and this self awareness is achieved, in turn, by self reflection (Spence et al., 2001, p194) This core skill of architectural practice is often developed with experience over time during a process of 'reflection-in-action' to use Schön's well-worn phrase (Schön, 1984). The design studio provides the environment to develop this skill in relation to design work, but how can we develop the same skill in the parallel practice and management curricula?

\section{Reflective Thinking in Teaching and Learning}

The value of reflective thinking as a way to transcend and enhance formal teaching is well-established in pedagogical wisdom (Dewey, 1933; Kolb, 1984). Goward (2009) has identified its value in entrenching a deeper learning in an academic construction management context and Roberts (2008) also notes its benefits in relation to architectural and construction management studies. Drawing on this experience and the practices of educators across a variety of disciplines, it can be assumed that teaching reflective thinking to built environment students is likely to be valuable in enhancing learning in relation to the architectural practice and management curriculum.

However, reflective learning cannot be taught as a skill merely by lecturing students on its content and validity. Instead, reflective thinking should be introduced to students prior to their transition from an institutional to a professional environment as a skill which they will continue to use as they develop in practice. It is not the skill that is taught but the development of "a capacity to process information during action" (Moon, 1999, p. 46 [emphasis added]). 


\section{The Inter-connected Learning Environment}

The e-learning environment is being increasingly selected as a vehicle for facilitating reflective thinking and practices. Perhaps it is the fact that the e-learning environment puts students in control of their own learning space - a key requirement if a focus on the self is the objective, as is the case for reflective processing. Furthermore, the elearning environment offers a vehicle which is more conducive to the ways that students manage information in the $21^{\text {st }}$ century. The phenomenon of networking sites such as Facebook, MySpace or Twitter are evident as a ubiquitous tool to share thoughts and ideas. The impact on students' social and academic life is all too evident to lecturers who may frequently observe these applications minimised in students' system tray during workstation based classes. Similarly, the popularity of hardware such as the iPhone, even amongst today's cash strapped undergraduates, points to the cultural significance of being able to share thoughts and ideas on the go, whether these be related to football scores, weekend plans or the stresses of final year deadlines. The new inter-connected environment in which today's student lives and learns is now sufficiently developed and readily accessible to be exploited by educators who wish to encourage learning, based on real-time thoughts and observations.

David Sifry noted in 2007 that "the state of the Blogosphere is strong, and is maturing as an influential and important part of the web" and reported Technorati's estimations that there are 70 million blogs in existence with 1.4 new blogs every second. Blogging is not only used to communicate individuals' manifestos, but has also been formalised by organisations supporting professional practice. For example, the British Medical Journal (BMJ) hosts a well-populated blog facility where medical practitioners and students can support ongoing reflective learning in relation to the trials of practice within the national health system and questions of bioethics. However, whilst the RIBA and Architect's Journal offer a similar facility, it is not well used and limited mainly to news roundup. Nevertheless, individual architects across the globe are posting about key issues in design and practice from sustainable urbanism to the aesthetics of skyscrapers. So successful is this medium, that "Bldgblog" has compiled posts into a published book.

Following the successful example demonstrated by the BMJ, it appeared timely and relevant to exploit the blogosphere as a place for reflective thinking as part of the architectural management module delivered to third year architectural technology students at the University of Central Lancashire. The majority of the students were part-time, spending the rest of their week in placement in architectural practices.

\section{The Brief}

Students were first introduced to the brief and also to the definitions and benefits of developing their skills in reflective thinking. The brief asked students to complete a reflective blog using an online facility set up centrally by the Learning Development Unit at the University of Central Lancashire. This facility provided a single point of contact 
for technical support which lifted this responsibility away from the module leader who could then focus on teaching and learning outcomes. This technical support was able to set up the blog accounts simply and promptly using only the students' university email addresses. Each student then received a username and password and was subsequently free to commence writing. In two cases, however, financial difficulties had prevented students from accessing the blog due to their accounts being 'frozen' until fees had been paid. This had to be resolved rapidly to enable these students to maximise the learning potential of the assessment.

To satisfy the assessment requirements, students were asked to make blog entries on a weekly basis relating to their involvement in teamwork activities. These activities could either be related to their academic work; their work in placement or indeed, any activity that required an outcome to be generated in a group setting. Students were also asked to respond constructively to one or more of their colleagues' blog entries, also on a weekly basis. Finally, students were asked to use a given set of tags i.e. keywords that could be used to search or group posts. These tags were derived from the architectural management module content relating to the 'soft' skills of design practice (see Appendix 1). Hence, the tags enabled students to focus their reflections within the associated learning outcomes of the module.

Importantly, this brief was kept succinct to these requirements. Beyond the assessment requirements, students were given the freedom to create their own profiles, themes and forms of expression within the blog group. It was hoped that this would transfer the perception of ownership of the assessment from the typically lecturer-led to student-centred. This was intended to give students the freedom and confidence to express themselves, offering an environment more conducive to personal reflection as well as enhancing individual engagement in the project.

\section{Assessment}

The blog was carried out over a period of one semester (September to December) with input from the lecturer only by way of defining a blog group within the software (see Figure 1: Blog Group Title Page); adding a welcome post and also to assist with technical difficulties. Following the deadline, the entries were assessed using a prepared rubric which allocated marks in the following categories:

1. Regularity of entries

2. Regularity of response to colleagues' entries

3. Level of reflection (using adapted rubric presented by Bain et al., 1999, cited in Roberts, 2008)

4. Quality of entry (based on writing style, punctuation and expression)

5. Use of tags from set list 
The assessment criteria demonstrate that only two elements of assessment were based on a qualitative input. i.e. criteria 3 and 4 . These criteria aimed to encourage students to apply their skills in writing and expression to capture and communicate their thoughts, which in turn would enhance the scope for reflective thinking. The remaining assessment criteria were deliberately constrained to quantitative elements that assessed the level of engagement with the learning outcomes rather than whether one student was a better blogger than another. This, again, was intended to promote personal and independent reflective thought without the shackles of trying to deliver what they thought the lecturer wanted to see. To state simply - by reflecting on their experiences and those of others with regularity and within the subject of teamworking, students were likely to fulfil the learning outcomes and attain the necessary grade.

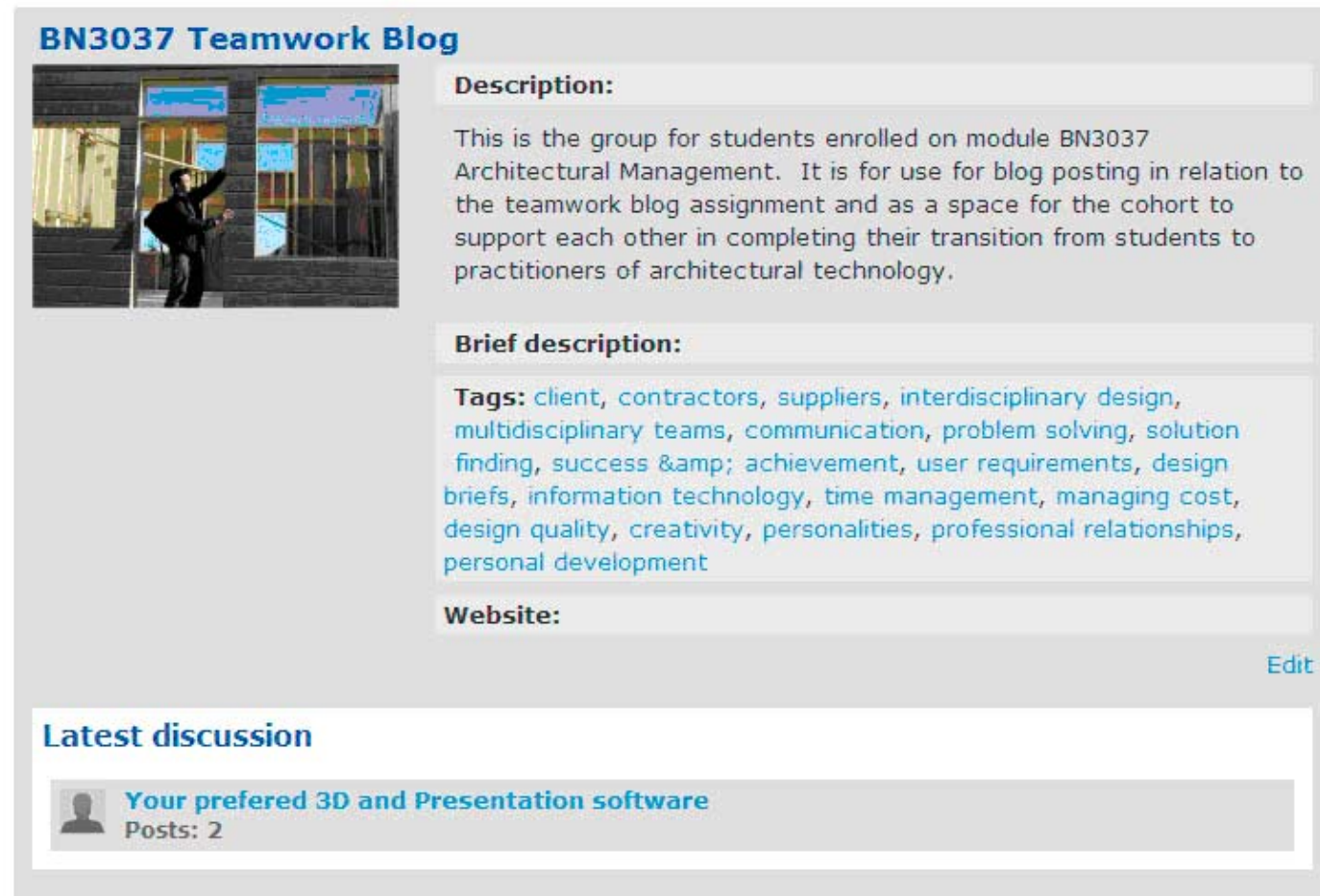

\section{Figure 1: Blog Group Title Page}

\section{Outcomes}

As technical support was provided centrally and thus any technical hitches were resolved directly with the student, for the module leader the assessment management workload remained lighter than that typically associated with assessment of a traditional essay, for example. Whilst the module leader reads the blogs regularly, to date there has been no misuse and hence, no requirement to moderate. As assessment criteria were primarily quantitive rather than qualitative, no detailed reading or feedback was required so the output was relatively quick to mark and the personalised nature of the writing made it equally entertaining to read. 
Of the 28 students who have completed the blog assessment to date, the majority have demonstrated week by week improvement of their reflective thinking skills. Using the adapted rubric for assessing level of reflection for assessment criteria 3 of the brief, most students were seen to improve their marks in this area during the semester - see Table 1.

Table 1: Students' performance relating to reflective thinking

\begin{tabular}{lcc}
\hline & Number & Percentage \\
\hline Students improved & 18 & $64.3 \%$ \\
Students consistent & 6 & $21.4 \%$ \\
Students failing to gain a pass & 4 & $14.3 \%$ \\
TOTAL & 28 & $100 \%$ \\
\hline
\end{tabular}

Overall, there was a clear progression in student's reflective thinking skills. Some students demonstrated that they were already skilled in reflection on their actions whilst some struggled in the initial weeks. Those who were less skilled began their blogs ruminating in a factual and non-reflective way on issues such as the capabilities of certain software or by simply listing what they had achieved that day. However, the requirement to read and respond to their colleagues' blog entries played a role in the development of their reflective thinking skills. By allowing the lesser skilled students to observe and learn from their peers, the blog encouraged peer support amongst the group and generated a valuable and efficient source of peer learning which required no further effort on the part of the more skilled students (see Figure 2: Sample Student Blog with Peer Comment). Of the students who failed to gain a pass in this assessment, individual discussion revealed that all of these students had problems relating to course engagement across the programme.

Their improvement may also be attributed simply to practise over the course of the semester and students commented upon the value of the exercise for enhancing their confidence, skill and interest in their subject. The successful engagement can be inferred from the direct quotes from blog entries, below:

Well, it's been an interesting exercise, if sometimes for me a slow process (slow blog = a slog?), but all things must end. Since starting this blog about drumming in a band I've improved individually as a drummer and, hopefully, collaboratively as a team member. Together we've written new songs, broadened our style, decided on a new band name and had fun. I feel I know a little more about teamwork, myself, the others in the band and fellow community members from our reflective blog.

When we set this task of reflective thinking through a blog, using tags I was a little concerned in how I would be able to achieve this task with not being in a 
practice. However by just taking a step back and perhaps looking at the tags from a different angle I used my experience in life and the different work I have done to respond. The success of completing this diary has been an achievement with the added bonus of learning/ hearing the views from other team members also it has provided food for thought in the future.

It must say a lot when you turn to a module-based blog for a breather from assignments?!

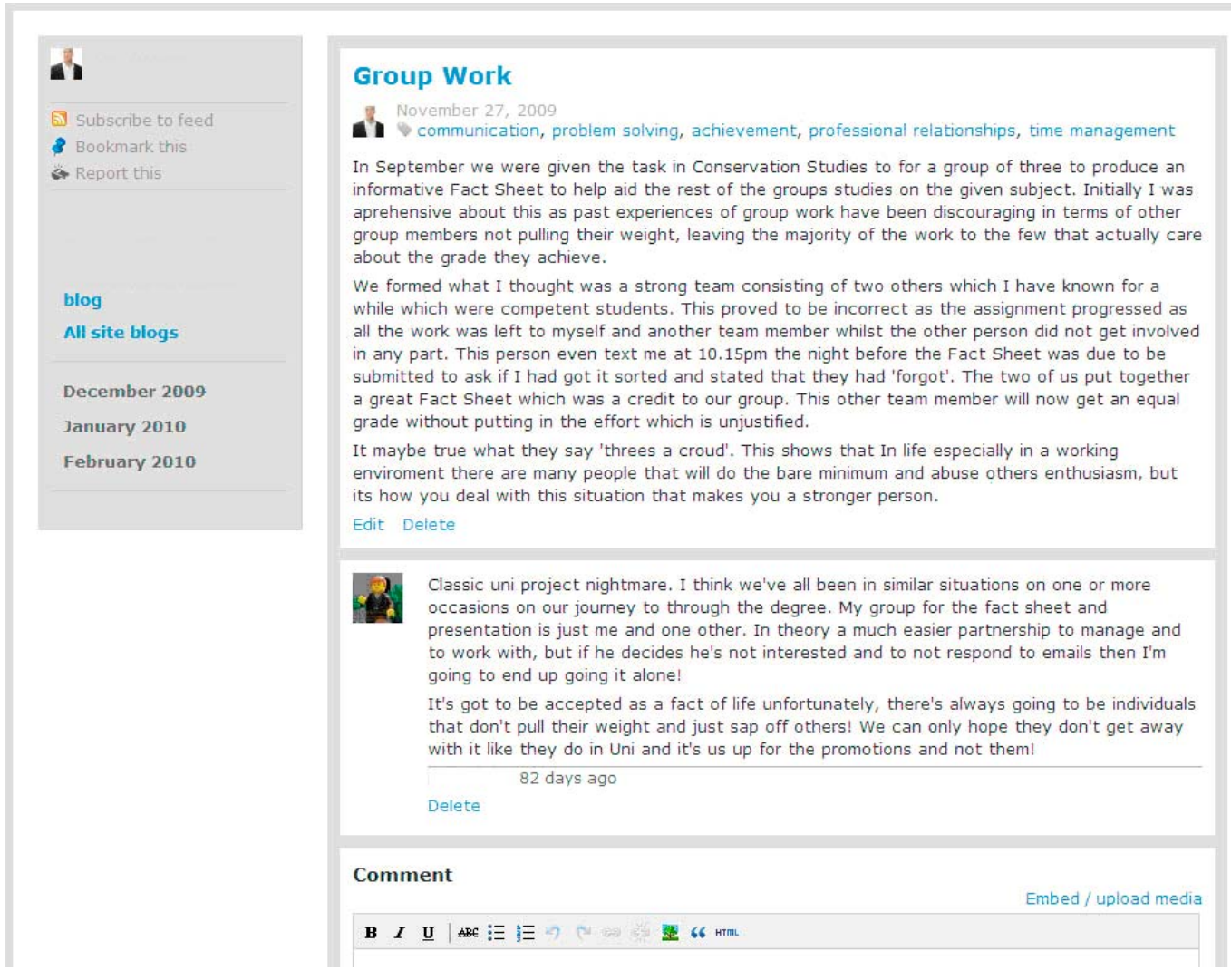

Figure 2: Sample Student Blog with Peer Comment

The completed assessment demonstrated clear value to students in a number of areas including those which were hoped for as well as some that were not predicted. From their entries, the students had obviously enjoyed the blogging experience and had said that it was easy to use, being easily integrated into their 'normal lives.'

An unexpected outcome of the assessment was the sense of community that the blog group created and this transcended the boundaries of the architectural management module to provide benefits across the whole programme. As previously mentioned, the majority of students in the cohort were part-time, spending the remainder of the week in placement. Some students only attended university and met their colleagues once a week. By creating a blog community, communication and support between students 
continued through the week providing a constant and more cohesive peer group than had been experienced in previous cohorts. This enhanced group cohesion meant that students felt more confident to speak up and discuss topics in class. This emerged from the sense of belonging to a supportive peer network. Whilst other initiatives in the university also sought to promote this sensibility, it is evident that the blog community provided a valuable contribution. The strong group cohesion paid particular dividends towards the end of the academic year as students supported each other towards the deadline of their degree show.

Another outcome which had been tentatively predicted was the improvement to the students thinking and learning during the formal lectures and tutorials. The students had developed their reflective thinking skills as part of the blog and this allowed them to consider the implications of the subject matter which was presented to them. They were now well used to applying their own experiences as well as those of others to real examples within the recent experience of their class and gain a deeper understanding of the issues under discussion. In effect, as students reached the end of their university careers, reflection-in-action was becoming a more instinctive behaviour.

For example, the architectural management module includes a tutorial on the subject of procurement routes for building projects. The subject content typically lists the different types of procurement routes from the traditional building contract to more complex PFI methods. The tutorial explained these different routes and the associated benefits, limitations and applications. The students, as in previous years, were then asked to think about their final year design project in which they were approaching the detailed design phase. Students in this cohort were better able to consider which route would be more suited to their project, not just in terms of the usual project tensions between time, cost and quality, but also to the ways that the team should be constructed to gain better integration and generation of commercial, aesthetic and functional excellence in the design process. Previously, in this well-trodden tutorial, students usually struggled to draw parallels with their stand alone design project and their own experiences in achieving success in teams and this usually resulted in a superficial fact-based learning on the subject. This time, however, having completed the blog, students were able to gain a deeper learning of the effective application of the procurement routes in relation to team processes as they were able to draw on their recent reflections on activities that had clear lessons in working as an integrated team, whether this be by being captain of an under-performing football team (see Figure 3: Using personal life for professional learning), playing in a struggling rock band or working to a deadline in their practice placement. 


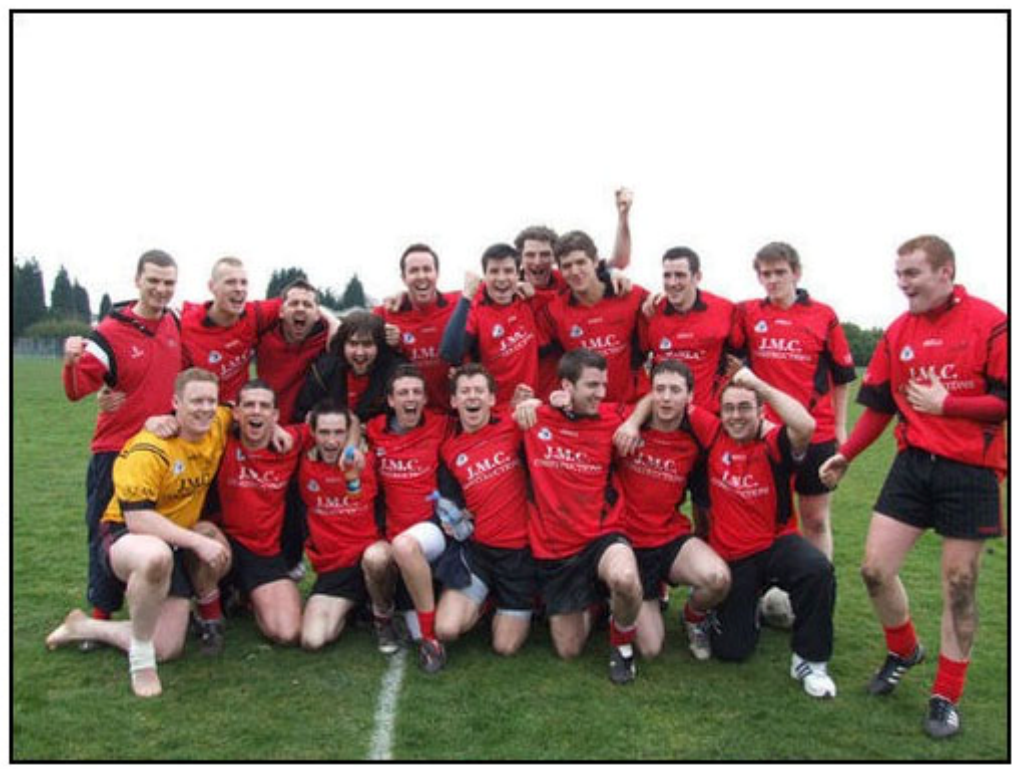

As some of you may know i play gaelic football for UCLan. Last weekend we had a game against Manchester met. The Game started off well for us as we took a 4 point lead. Things where lookin good until 10 mins before half time one of our players was sent off for a second bookabkle offence. This give the opposition the upper hand as there was a big gap in defence and they where picking off scores for fun and took the lead from us before halftime. At the break we all huddled together and discussed our feelings and how we could get ourselves back into the game. I was currently playing in Full forward and i volunteered to go back and mark the spare man which would mean we would have less attacking players and strugle to score. The team also came to an agreement that we had to adapt or tactics that where workin well for us before the sending off. We decided that we would need to play a shorter fist passing game. So we lined out for the second half with a man less and 2 points behind. From the whislte everyone stepped up their perfomance and give $100 \%$ and we ended up winning the game by 3 points against one of the best teams in England. The feeling after that game was unbelievable as we had no right to win that game. Since this game morale has been very good in training as we knew that we had showed guts and character when we had our backs against the wall. We all believe now that we have the potential to win the brittish championship which in the game of gaelic football is a great achievement.

Edit Delete

Figure 3: Using personal life for professional learning

\section{Conclusions}

The reflective blog assessment proved extremely valuable for teaching and learning in the architectural management module and the exercise will certainly be repeated for future cohorts. In 2009, the University of Central Lancashire commenced its new BSc Architecture programme. This assessment will be tailored and run for these new students too.

In summary, there are a number of best practice points to be gleaned from the pilot to ensure success. These are collected below: 


\section{The brief}

Do not prescribe content to students. Limit the brief to guidance on reflective style, assessment criteria and technical support. The use of set tags will enable students to focus their discussion within the subject area.

\section{Moderation}

The assessment leader should moderate the blog at regular intervals to ensure that the facility is not being misused. Apart from this the ownership of the blog site should remain with the students involved.

\section{Assessment}

Minimise the use of qualitative judgement criteria in the assessment rubric, as far as possible. Reward should be given for engagement and application of a reflective thinking style rather than attempting to rate the quality or depth of reflection.

\section{Facilitating collective learning}

Involvement and response to each other's posts should be encouraged, whether by assessment or by class discussion to aid group cohesion and peer to peer learning.

\section{Consolidation during tutorial}

The students' developing reflective thinking skills should be encouraged beyond the assessment to class discussions. By taking advantage of the parallels in experience and true reflections on actions, a deeper learning experience is more likely.

\section{Future Development}

There is scope to develop the assessment method further. The use of the tags was never fully explored beyond constraining students' thoughts within a manageable subject area - in this case, teamworking.

However, this year, the tags will be used to generate class discussion on the themes generated by the blog posts. The blog facility allows the lecturer to identify which tags were used most frequently and who used them. Hence, students can be grouped for discussion according to the tags that they used the most - that is to say, the issue which presented most challenges in need of reflection. For example, the students who reflected frequently upon the challenges of client relationships will be instructed to discuss their experiences and produce a good practice guide as an outcome of their collective thought. Furthermore, the thinking space afforded by the e-learning environment will be further exploited to present their good practice guide as an online 'wiki.' Hence, the cohort will be guided in sharing a solution-based and student-centred approach to teamworking best practice based upon their own experiential learning, yet supported by academic guidance. 
The new architecture course at the University of Central Lancashire is also considering the use of the reflective blog as a student-centred outcome of the year out placement. Students will then be facilitated in reflecting on their architectural practice experience as a contribution to their professional studies at Masters level. Could the reflective blog be developed to provide a more educationally valuable and more accessible, userfriendly alternative to the RIBA Practical Experience Development Records (PEDRs)? An idea to reflect upon, I think! 


\section{References}

Bain, J. D., Ballantyne, R., Packer, J. \& Mills, C. (1999) Using journal writing to enhance student teachers' reflectivity during field experience placements. Teachers and Teaching, 5 (1), 51-73.

Dewey, J. (1933) How we think: A restatement of the relation of reflective thinking to the educative process. London: D.C.Heath.

Egan, J. (1998). Rethinking construction the report of the Construction Task Force to the Deputy Prime Minister, John Prescott, on the scope for improving the quality and efficiency of UK construction. London: Department of the Environment, Transport and the Regions.

Goward, T. (2009) Learning through teamwork. CEBE Transactions, 6 (1), 18-37.

Kolb, D. A. (1984) Experiential learning: Experience as the source of learning and development. Upper Saddle River, NJ.: Prentice-Hall.

Moon, J. A. (1999) Reflection in learning and professional development: Theory and practice. London: Kogan Page.

Roberts, A. (2008) Recording and reflecting on workplace experience. CEBE Briefing Guide No. 13. Cardiff: Centre for Education in the Built Environment.

Schön, D.A. (1984) The reflective practitioner: How professionals think in action. New York: Basic Books.

Sifry, D. (2007) State of the blogosphere. Available on line at: www.sifry.com/alerts/archives/000493.html (accessed 24 February 2010).

Spence, R.; Macmillan, S. \& Kirby, P. (2001). Interdisciplinary design in practice. London: Thomas Telford.

\section{Blogs:}

Architects' Journal (Hattie Hartman's Sustainability Blog): http://blog.emap.com/footprint/

Bldgblog: http://bldgblog.blogspot.com

British Medical Journal: http://blogs.bmj.com

RIBA Blog: http://www.ribablogs.com/?page id=2 


\title{
Appendix 1: Tag List
}

\author{
Client \\ Contractors \\ Suppliers \\ Interdisciplinary design \\ Multi-disciplinary teams \\ Communication \\ Conflict \\ Problem solving \\ Solution finding \\ Success \& Achievement \\ User requirements \\ Design Briefs \\ Information Technology \\ Time management \\ Managing Cost \\ Design quality \\ Creativity \\ Personalities \\ Professional relationships \\ Personal development
}

